\title{
PENDAMPINGAN PENGEMBANGBIAKAN USAHA JAMUR TIRAM MASYARAKAT DESA LONKEBUN Kerjasama dengan Yayasan Nailun Najah Desa Lonkebun Kecamatan Ketapang Kabupaten Sampang
}

\author{
Oleh : \\ Maryam Qadarin', M.Rodiaminullah ${ }^{2}$, Faqih $^{3}$, Sony Firmansyah ${ }^{4}$, \\ Rofiqoh $^{5}$, \& Khairil Anwar 6 \\ Dosen IAI Nazhatut Thullab Sampang1,2,3,4 \\ Mahasiswa IAI Nazhatut Thullab Sampang5,6 \\ Email : maryamqadarin@gmail.com ${ }^{1}$, rodiamin07@gmail.com ${ }^{2}$, sonyfm@gmail.com ${ }^{3}$
}

\begin{abstract}
Abstrak
Tujuan pengabdian ini ialah untuk memberdayakan masyarakat dengan budidaya jamur tiram serta pengolahan dengan harapan dapat meningkatkan kesejahteraan masyarakat desa Lonkebun kecamatan Ketapang kabupaten Sampang. Metode dalam kegiatan ini terdiri dari: Pemberian Materi tentang budidaya jamur tiram serta cara mengolah; Praktik budidaya jamur tiram ; dan evaluasi. Kegiatan Pengabdian ini dilakukan pada bulan Oktober sampai November 2020 Pelaksanaan kegiatan dengan melibatkan beberapa dosen dan mahasiswa. Hasil evaluasi dari kegiatan ini menunjukkan bahwa masyarakat sudah dapat melakukan budidaya jamur tiram dan mengolahnya secara mandiri. Masyarakat sangat respon terhadap kegiatan ini.
\end{abstract}

Kata kunci : jamur tiram, budidaya,

\begin{abstract}
The goal of this engagement was to empower communities by cultivating oyster mushrooms and processing it into products so that they can improve the welfare of Lonkebun village, Ketapang, Sampang. The method of this engagement consists of: workshop about the cultivation of oyster mushrooms and the processing,; Practice of oyster mushroom cultivation; and evaluate. This service activity was carried out in October through November 2020, where several lectures and students perform the performance. The results of this activity showed that people can grow oyster mushrooms and manage them independently. The public is very responsive to this activity
\end{abstract}

Key words: oyster mushrooms, cultivation. 


\section{PENDAHULUAN}

Pertumbuhan ekonomi nasional kerap ditandai dengan meningkatnya produktivitas pendapatan secara nasional atas kegiatan-kegiatan ekonomi yang berlangsung pada suatu negara. Salah satu hal yang paling mudah dapat dilihat dari pertumbuhan ekonomi yaitu berkaitan dengan tersedianya lapangan kerja, akses pendidikan, pendapatan masyakarat dan sebagainya. Oleh karena itu, berbagai kegiatan ekonomi baik dalam skala makro, meso ataupun mikro menjadi penyumbang bagi pertumbuhan ekonomi nasional.

Secara umum ekonomi kerakyaratan merupakan pondasi atas kemajuan ekonomi dalam skala besar. Logika sederhana yang dibangun bahwa tidak ada yang tumbuh besar tanpa ada yang kecil. Untuk itu berbagai negara termasuk Indonesia cukup konsen memberdayakan ekonomi kerakyatan dalam meningkatkan pertumbuhan ekonomi nasional. Program-program pemberdayaan ekonomi kerakyatan dimaksudkan mensinergikan berbagai program dengan harapan mampu mengembangkan masyarakat secara utuh. ${ }^{1}$ Lebih lanjut pemberdayaan ekonomi dalam hal ini pada dasarnya merupakan usaha untuk mampu memulihkan atau meningkatkan keberdayaan suatu kelompok atau komunitas sehingga mampu berbuat sesuai dengan harkat dan martabatnya dalam melaksanakan hak-hak dan tanggung jawabnya sebagai manusia pribadi ataupun warga negara. Nilai-nilai manusia sebagai pribadi yang mandiri perlu dikedepankan dalam segala aspek kehidupan termasuk perihal membangun ekonomi kerakyatan.

Berdasarkan penjelasan di atas terlihat pengelolaan perekonomian nasional khususnya terkait dengan pemberdayaan ekonomi kerakyatan merupakan hal yang urgen untuk diagendakan. Ekonomi kerakyatan yaitu usaha menggerakkan aktivitas

${ }^{1}$ https://kominfo.go.id/content/detail/6957/pemerintah-susun-program-ekonomi-

kerakyatan/0/sorotan_media diakses pada 13 April 2019 
ekonomi rakyat, terutama usaha kecil dan menengah yang dilakukan oleh rakyat banyak, untuk kemudian hasilnya pun akan kembali kepada rakyat. Karena sifatnya yang merata, persebaran modal yang baik, sistem ekonomi yang benar-benar bergerak dalam sektor riil, ekonomi rakyat mempunyai dampak pemerataan terhadap pendapatan yang baik dan mampu menggerakkan sektor riil secara efektif. ${ }^{2}$

Definisi tersebut menegaskan bahwa pemberdayaan lebih mengarahkan kepada penguatan terhadap rakyat untuk dapat berpartisipasi dalam proses pengambilan keputusan yang mempengaruhi kehidupannya khususnya pada lingkup ekonomi sehingga rakyat dapat benar-benar dapat terbedayakan sesuai dengan hakikatnya sebagai warga negara. Desa Lonkebun adalah salah satu dari desa Ketapang kecamatan Ketapang kabupaten Sampang provinsi Jawa Timur dengan letak geografis

$3.99 \mathrm{~m}^{2}$ dan memiliki empat dusun yakni desa Lonkebun, Kokkowan, Kristal dan Ketapang Timur. Mayoritas masyarakat Desa Lonkebun adalah petani. Meraka mengandalkan pendapatan dari hasil panen pertanian. Ini bisa dilihat dari masih luasnya lahan persawahan yang ada di Desa Lonkebun. Komoditas pertanian di dusun ini sama halnya dengan komoditi pertanian yang ada di wilayah Madura pada umumnya yaitu jagung, padi, mentimun, kacang panjang, kacang tanah, dan juga tembakau.

Keadaan sosial ekonomi masyarakat desa Lonkebun termasuk dalam menengah kebawah. Keadaan ini disebabkan berbagai faktor diantaranya keterbatasan sumber penghasilan karena mayoritas masyarakat hanya mengandalkan hasil pertanian system tradisional yang sangat tidak menentu bahkan sebagian lahan di dusun ini merupakan lahan yang sangat tandus dan hanya bisa ditanami saat musim hujan. Masyarakat desa Lonkebun tampaknya kurang memiliki kreativitas dalam

2 Bayu Krisnamurthi, Krisis Ekonomi Moneter dan Ekonomi Rakyat, dalam Jurnal Ekonomi Rakyat, Tahun 1, No 3,2002 
pengembangan usaha pertanian. Secara turun temurun mereka menanam komoditi pertanian yang sama dengan system pertanian yang sama pula. Kurangnya kreativitas masyarakat ini dikarenakan kurangnya pengetahuan mereka akan inovasi-inovasi dalam bidang pertanian. Informasi mengenai inovasi tersebut bersumber dari berbagai arah seperti media social, pihak eksternal masyarakat yang memberi pelatihan, pihak internal yang aktif mencari pelatihan di luar serta informasi melalui bangku pendidikan.

Namun permasalahan ekonomi yang dialami masyarakat ini berdampak pada berbagai aspek kehidupan utamanya pendidikan. Seperti yang telah dijelaskan pada sub bab kondisi pendidikan bahwa tingkat kesadaran pendidikan masyarakat Ketapang termasuk desa Lonkebun pada umumnya rendah. Rendahnya tingkat pendidikan ini dapat mengakibatkan rendahnya kualitas SDM (Sumber Daya Manusia). Dampak buruk dari rendahnya kualitas SDM salah satunya adalah ketidakmampuan masyarakat untuk meningkatkan kualitas kehidupannya seperti perekonomian. Dari uraian tersebut dapat disimpulkan bahwa permasalahan perekonomian dan pendidikan adalah dua hal yang saling berkaitan.

Dengan latar belakang keadaan tersebut maka penulis selaku sivitas academia IAI Nazhatut Thullab Sampang merasa perlu untuk bergerak, melakukan suatu tindakan nyata untuk menggerakkan ekonomi rakyat karena masyarakat dengan perekonomian yang baik merupakan cita-cita nasional. Merujuk kepada Pasal 33 UUD 1945 dimaksud terlihat jelas bahwa sistem perekonomian nasional Indonesia ditujukan untuk kesejahteraan sosial ${ }^{3}$. Oleh karena itu diharapkan setiap lapisan masyarakat baik dipedesaan maupun diperkotaan memiliki kesejahteraan yang sama. Langkah yang dapat dilakukan untuk meningkatkan perekonomian masyarakat desa

${ }^{3}$ Zainal Arifin Hoesein, "Peran Negara Dalam Pengembangan Sistem Ekonomi Kerakyatan menurut UUD

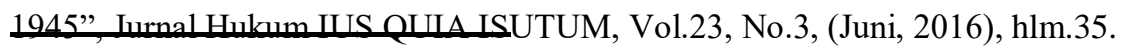


Lonkebun yaitu dengan pengembangan kemampuan (skill) dibidang pertanian melalui inovasi komoditi pertanian berupa budidaya jamur tiram.

Pemilihan budidaya jamur ini karena mayoritas profesi masyarakat desa Lonkebun sebagai petani dan mengingat jumlah air yang tidak terlalu banyak, Selain itu nilai ekonomis jamur tiram yang tinggi dengan kisaran harga Rp 20.000 sampai dengan $\mathrm{Rp}$ 30.000 per $1 \mathrm{~kg}$ dengan permintaan terhadap jamur juga cukup tinggi karena jamur dapat diolah menjadi berbagai jenis olahan seperti jamur krispi, sup dan campuran kue basah. Dari pemaparan tersebut maka penulis berkeyakinan bahwa usaha budidaya jamur tiram merupakan usaha yang tepat untuk meningkatkan ekonomi rakyat desa Lonkebun kecamatan Ketapang kabupaten Sampang.

\section{METODE PENGABDIAN}

Untuk memecahkan masalah yang telah diidentifikasi dan dirumuskan diatas, maka pelaksanaan kegiatan pengabdian ini dilakukan dengan menggunakan metode pelatihan dan pendampingan, dimana kedua metode tersebut dilakukan dengan cara :

a. Ceramah / Pemberian Informasi dan simulasi; Kegiatan ini dimulai dengan pemberian informasi dengan menggunakan metode ceramah sekaligus memberikan simulasi kepada masyarakat berkaitan dengan :

- budidaya jamur tiram yang terdiri dari pembuatan kumbung (bangunan tempat menyimpan baglog), pembuatan baglog (media tanam), penanaman bibit jamur, perwatan tanaman jamur.

- Pengolahan jamur dalam bentuk jamur krispi dan isi resol

Kegiatan ini dilakukan dengan harapan masyarakat memiliki pemahaman yang baik terkait budidaya jamur tiram sekaligus pengolahan dan bisa mengaplikasikannya dalam praktek.

b. Diskusi / Tanya jawab; metode ini digunakan agar masyarakat bisa bertanya tentang hal-hal yang belum mereka fahami dan menjadi polemik diantara mereka. 
c. Pendampingan; dalam kegiatan ini kami mendampingi masyarakat secara langsung di lapangan untuk memulai budidaya jamur tiram serta pengolahannya.

\section{HASIL DAN PEMBAHASAN}

\section{Pelatihan Budidaya Jamur}

Tema program PKM tematik ini adalah Pendampingan Pengembangbiakan Usaha Jamur Tiram Masyarakat Desa Lonkebun Kerjasama dengan Yayasan Nurul Huda Desa Lonkebun Desa Ketapang Kecamatan Ketapang Kabupaten Sampang dengan fokus bidang perekonomian. Berikut uraian mengenai kegiatan pendampingan yang dimaksud.

a. Pembuatan Kumbung

Kagiatan pendampingan ini dimulai dari proses yang paling awal pada usaha budidaya jamur yaitu pembuatan kumbung berukuran $3 \times 4$ meter sebagai tempat menyimpan baglog. Kumbung merupakan bangunan berdinding anyaman bambu dan berventilasi. Kumbung ini dibangun di halaman samping Yayasan Nailun Najah. Pemilihan lokasi ini dengan pertimbangan bahwa kiai sangat berpengaruh terhadap kehidupan social masyarakat. Sehingga harapannya hasil dari kegiatan pemberdayaan masyarakat ini dapat berlangsung seterusnya melalui himbauan kiai kepada masyarakat desa Lonkebun. Pembuatan kumbung ini diikuti oleh kurang lebih 20 masyarakat setempat baik perempuan maupun laki-laki

Di dalam kumbung tersusun 26 rak tempat baglog jamur tiram. Rak di dalam kumbung disusun sedemikian rupa sehingga memudahkan dalam proses pemeliharaan jamur dan perputaran udara terjaga. Jarak antara satu rak dengan rak lainnya kurang lebih $50 \mathrm{~cm}$. lebar rak $50 \mathrm{~cm}$, tinggi rak $1.5 \mathrm{~m}$, panjang disesuaikan dengan kondisi ruangan. Setiap ruas rak bisa memuat 20-80 baglog. 




b. Menyiapkan Baglog

Kegiatan selanjutnya yaitu menyiapkan baglog sebagai media tanam jamur. Baglog pada umumnya dibungkus plastik berbentuk silinder dan salah satu ujungnya diberi lubang. Dari lubang tersebutlah jamur tiram akan tumbuh ke luar. Berikut bahan yang dibutuhkan untuk membuat 80 buah baglog : serbuk gergaji $10 \mathrm{~kg}$, tepung jagung 0,6 kg, dedak halus $15 \mathrm{~kg}$, pupuk TSP $1 \mathrm{~kg}$, kapur $2 \mathrm{~kg}$, pupuk organic cair GDM, air secukupnya. Setelah semua bahan masuk kedalam plastik kemudian plastic tersebut dipanaskan pada tungku untuk mensterilkan media tanam tersebut sehingga tidak ada jamur yang tumbuh selain jamur tiram Kegiatan ini dihadiri oleh 25 masyarakat sekitar baik laki-laki maupun perempuan. 


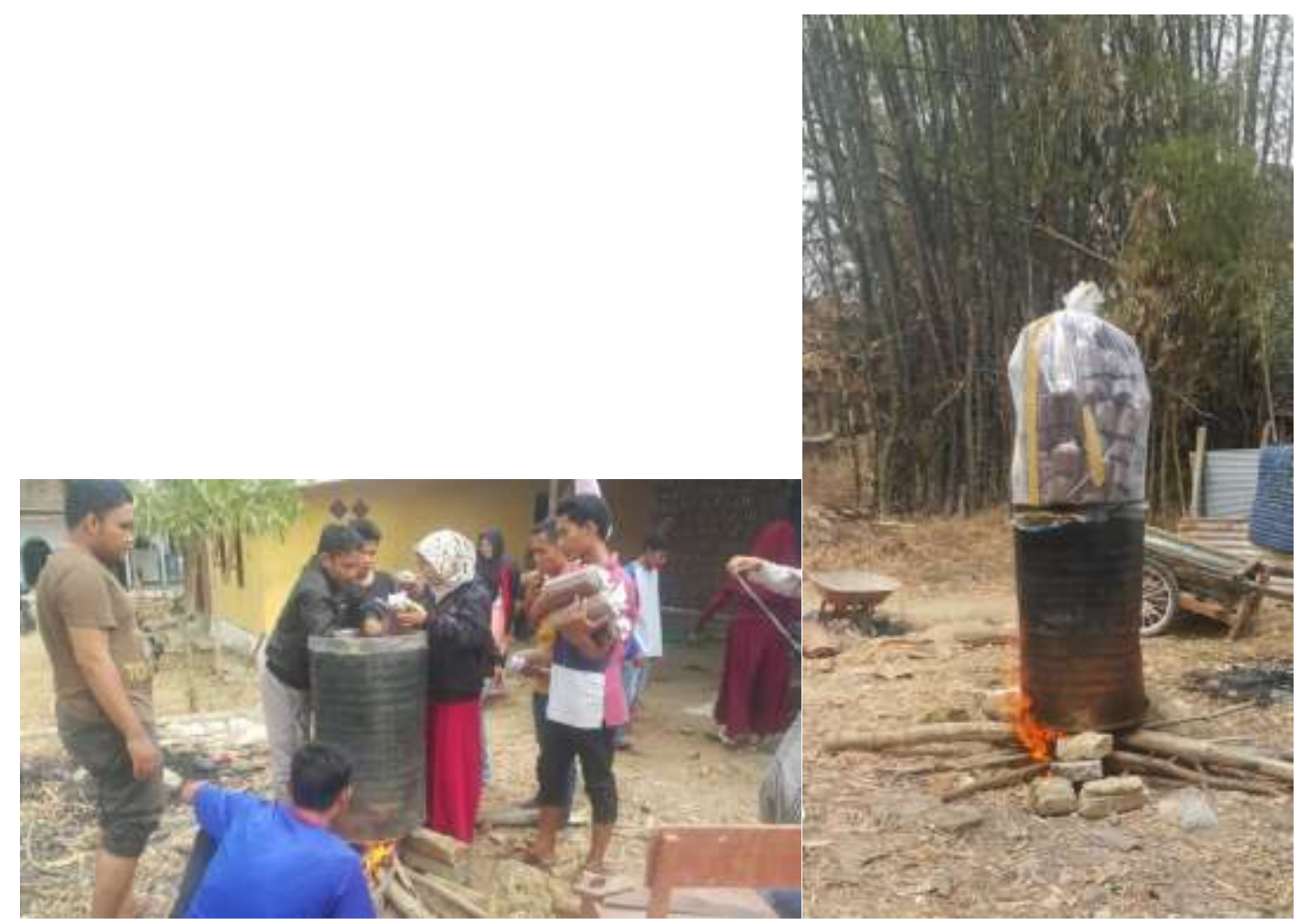

c. Penanaman Bibit Jamur

Hari berikutnya dilanjutkan dengan penanaman bibit jamur tiram. Proses penanaman bibit jamur tiram ini harus dilakukan dengan cepat dan teliti. Yang perlu diingat bahwa proses penanaman bibit jamur tiram harus dilakukan di tempat/ruangan yang tertutup. Berikut adalah cara penanaman bibit jamur yang bisa dulur terapkan:

- Siapkan baglog

- Berikan 3 sendok makan bibit ke dalam setiap satu baglog. Pada setiap gerakan sendok yang digunakan, panaskan terlebih dahulu sendok tersebut dengan menggunakan api untuk menghindari kontaminasi.

- Buka karet, kertas serta kapas penutup pada baglog

- Semprot isi ruangan secara merata menggunakan alcohol 95\% untuk menghindari tumbuhnya jamur yang tidak diinginkan. 
- Tata baglog yang sudah terisi bibit pada rak

- Kegiatan ini dihadiri oleh 28 masyarakat sekitar baik laki-laki maupun perempuan.

d. Perawatan Tanaman Jamur

Setelah seluruh baglog terisi bibit, maka kegiatan selanjutnya adalah proses perawatan jamur. Hal yang paling utama yang dibutuhkan jamur adalah kelembaban udara dalam kubung. Agar kelembaban terjaga maka petani jamur harus menyemprotkan air dan pupuk organic cair GDM dengan menggunakan alat semprot pada setiap baglog dengan dosis 1 gelas per tangki. Lakukan hal tersebut setiap hari. Jika seluruh baglog ditumbuhi jamur, tutup kapas dan cincin di bagian atas baglog tersebut dibuka. Jika jamur telah tumbuh dengan mekar dan lebar maka jamur sudah siap untuk dipanen. Kegiatan ini dihadiri oleh 25 masyarakat sekitar baik laki-laki maupun perempuan.

\section{Pengolahan Jamur}

Sebagai penutup kegiatan KPM ini, diadakan pelatihan pengolahan jamur menjadi berbagai macam jenis makanan seperti jamur krispi dan isi kue risol sebagai alternative pengganti daging ayam. Bahan yang dibutuhkan dalam pembuatan jamur krispi adalah tepung siap saji. Sedangkan untuk risol dibutuhkan tepung terigu untuk bahan kulit resol, wortel dan bawang merah sebagai isisan resol. Kegiatan ini dihadiri oleh 20 masyarakat sekitar mayoritas perempuan.
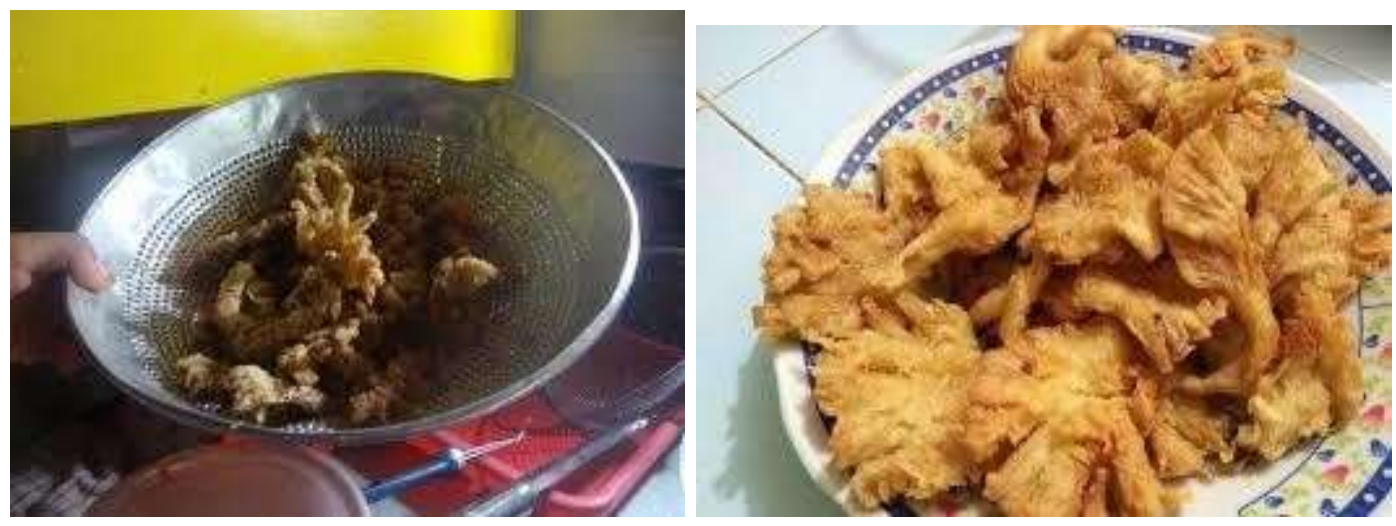


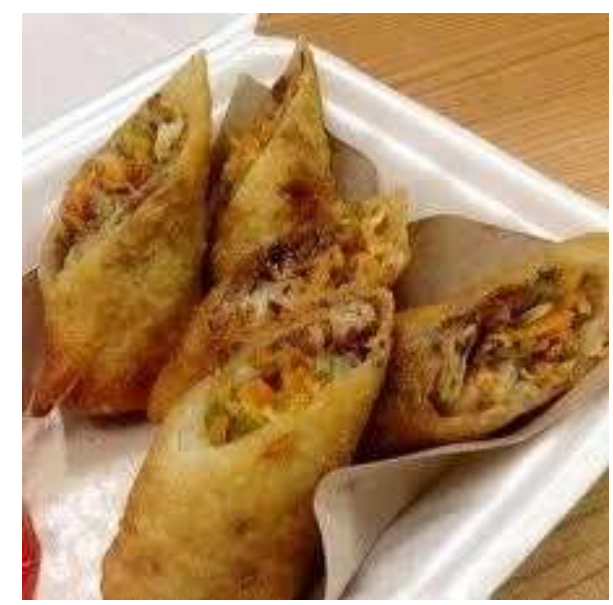

\section{KESIMPULAN}

Rangkaian kegiatan KPM yang dilaksanakan sejak Oktober hingga November 2020 disambut antusiasme masyarakat desa Lonkebun kecamatan Ketapang kabupaten Sampang. Hal ini dapat dilihat dari jumlah peserta pada setiap kegiatan yang terbilang cukup banyak dan konsisten. Peserta juga sangat aktif ikut serta dalam setiap proses budidaya jamur ini, bahkan mereka tidak segan untuk bertanya jika ada yang tidak dipahami.

Melihat proses budidaya jamur yang tidak membutuhkan modal besar tetapi dapat dilakukan dengan lahan kecil, air yang tidak melimpah dan minim perawatan serta permintaan pasar yang cukup tinggi dengan harga jual yang tinggi pula maka masyarakat dusun Tengginah berkeyakinan bahwa budidaya jamur dapat menjadi solusi dari masalah perekonomian yang selama ini dihadapi.

Program ini bertujuan tidak hanya menggali potensi yang telah dimiliki masyarakat dan memberdayakan masyarakat, namun agar memahami proses bisnis sesungguhnya yang seharusnya dapat dilalui seluruh masyarakat untuk dapat menjadi entitas bisnis dimulai dari skala kecil. Dari penjabaran di atas maka dapat disimpulkan bahwa seluruh rangkaian kegiatan KPM ini layak untuk dilanjutkan. 


\section{UCAPAN TERIMAKASIH}

Kami ucapkan terimakasih banyak kepada ketua yayasan Nailun Najah yang telah berkenan menjadi tempat pelatihan dan pendampingan budidaya jamur ini serta telah membantu dalam mengumpulkan masyarakat sekitar sebagai peserta pelatihan. Terimakasih juga kami sampaikan kepada kepala desa Loonkebun yang telah memberikan izin tim untuk melakukan kegiatan pengabdian ini. Dan terimakasih kepada masyarakat desa Lonkebun yang telah bersedia hadir dalam kegiatan ini. Semoga kerjasama ini membawa keberkahan.

\section{DAFTAR PUSTAKA}

Djarijah dan Abbas. Budidaya Jamur Tiram (Pembibitan Pemeliharaan dan Pengendalian Hama-Penyakit). Yogyakarta: Kanisius, 2001.

Hosein, Zainal Arifin, "Peran Negara Dalam Pengembangan Sistem Ekonomi Kerakyatan menurut UUD 1945”, Jurnal Hukum Ius Quia Isutum, Vol.23, No.3, (Juni, 2016)

Ibnu, Pemerintah Susun Program Ekonomi Kerakyatan, Kementrian Komunikasi dan Informasi RI, diakses dari https://kominfo.go.id/content/detail/6957/pemerintah-susun-program- ekonomikerakyatan/0/sorotan_media pada 13 April 2019

Krisnamurthi, Bayu, "Krisis Ekonomi Moneter dan Ekonomi Rakyat”, Jurnal Ekonomi Rakyat, Tahun 1, No. 3, (Februari, 2002).

Muad, Asegab. «Bisnis Pembibitan Jamur Tiram, Jamur Merang dan Jamur Kuping. Jakarta: PT Agromedia Pustaka, 2011

Tim, Kecamatan Ketapang dalam Angka, Sampang: BPS, 2016.

Unus, Suriawiria. Sukses Beragrobisnis Jamur Kayu: Shitake, Kuping, Tiram. Jakarta: Penebar Swadaya, 2000. 